\title{
AC 2012-3920: SCAFFOLDING PROVIDED TO ENGINEERING STUDENTS IN CORNERSTONE DESIGN PROJECT SCENARIOS RELATED TO PRAC- TICES OF EXPERT DESIGNERS
}

\section{Dr. Yosef S. Allam, Embry-Riddle Aeronautical University, Daytona Beach}

Yosef Allam is an Assistant Professor in the Freshman Engineering Department at Embry-Riddle Aeronautical University. He graduated from the Ohio State University with B.S. and M.S. degrees in industrial and systems engineering and a Ph.D. in engineering education. Allam's interests are in spatial visualization, the use of learning management systems for large-sample educational research studies, curriculum development, and fulfilling the needs of an integrated, multi-disciplinary first-year engineering educational environment through the use of collaborative learning, problem-based and project-based learning, classroom interaction, and multiple representations of concepts.

\section{Dr. Clifford A. Whitfield, Ohio State University}

Clifford Whitfield graduated from the Ohio State University with B.Sc., M.Sc., and Ph.D. degrees in aerospace engineering and is currently working as a Lecturer-B.E. and a Senior Research Associate for the Mechanical and Aerospace Engineering Department and the Engineering Education Innovation Center's First-year Engineering program at the Ohio State University.

\section{Miss Jintana Nina Phanthanousy, Embry-Riddle Aeronautical University}

Nina Phanthanousy is currently pursuing her master's degree in mechanical wngineering at Embry-Riddle Aeronautical University. She also received her bachelor's of science at ERAU in aerospace engineering, astronautics. 


\title{
Scaffolding Provided to Engineering Students in Cornerstone Design Project Scenarios Related to Practices of Expert Designers
}

\begin{abstract}
First-year engineering students involved in design projects, now commonly called "cornerstone" projects, are typically given various forms of scaffolding to support their learning at the postsecondary educational level as they gain the skills necessary to eventually conduct self-directed design projects as professionals. The scaffolding may appear to students in the form of a prescribed design process with discrete steps and iteration points; a skeletal project schedule requiring student project teams to fully populate and expand it; predetermined benchmarking and lab- or library-based investigation and research; partially worked, theoretical, predictive calculations to complete; kitted, limited equipment, materials, and tooling access; building; testing; instructor-prescribed or fault-driven design revisions, as well as other forced design iterations.
\end{abstract}

The purpose of this study is to investigate the scaffolding described above in terms of how it compares to the prescriptions of experienced designers in academia. This study also seeks to compare the proportion of time spent by first-year engineering students on typical design process activities and the sufficiency of student-designer iterations versus the importance placed on equivalent activities by faculty. In addition, this study discusses the ensuing questions regarding the disparity in time and effort placed by students on certain design process activities as compared to the importance of these activities as deemed by the faculty designers: How do students appropriate their time and efforts in the design process? How is student application of the design process related to the scaffolding provided? How do student design activities and the corresponding scaffolding supporting student design compare to the desired activities, habits, and prescriptions of experienced designers in academia?

In order to assess these objectives, surveys were conducted for novice designers (students). The student team-based anonymous surveys were conducted on a weekly basis throughout a termlength design for four distinct cornerstone projects, with 18 teams on each design project (72 total teams or approximately 288 total students) in the First-year Engineering Program within the Engineering Education Innovation Center at The Ohio State University.

Student cornerstone design teams were found to be spending at least $7 \%$ of their total time spent on each phase of the design and project management processes. Student teams also visited each phase of the design process at least 1.2 times per week throughout the term of the project.

Introduction

Freshman engineering design coursework, now widely termed "Cornerstone" experiences, began wide adoption in the 1990's and into the new millennium through the National Science Foundation's eight Engineering Education Coalitions, among other efforts. These first-year engineering design laboratories serve to complement the already established senior undergraduate level, or "Capstone" design experiences widely adopted in the 1980's at 
engineering colleges across the United States. The combination of the Cornerstone and Capstone coursework for beginning and graduating, respectively, undergraduate engineering students thus act as bookend design experiences. The Cornerstone curricula serve multifaceted purposes including providing students with what is likely their first open-ended design and long-term problem-solving challenge as well as transitioning incoming traditional engineering students from secondary college preparatory coursework to engineering coursework at the post-secondary level, not to mention satisfying various curriculum content-related and pedagogical objectives. The Capstone activities provide students with an opportunity to apply their coursework from their program of study and experiences through their college careers in a final project often in the field and involving industry partners before formally pursuing their chosen engineering profession.

Cornerstone design experiences incorporate project-based learning and serve to put engineering design up front early and often. Cornerstone project-based learning experiences feature characteristics such as being hands-on, team-based, term-length, with a project goal of generating a design and possibly a prototype or in-class implementation if a "build" component is incorporated. Cornerstone design experiences common to other instances of project-based learning integrate knowledge and skills from different fields, topics, or topic- or field-specific courses from students' program of study. Cornerstone laboratories serve the effort to move postsecondary engineering education away from traditional lecture of curricula segregated by topic. Properly designed cornerstone design projects can potentially address most, possibly all, of the ABET 2000 Criteria to varying extents throughout the project. Cornerstone design coursework supports constructionist pedagogical theory and incorporates instructional strategies that are student-centered and promote active learning while addressing a variety of learning styles ${ }^{1}$. Cornerstone curriculum designers and instructors accept that learning occurs as an active process where students construct their own knowledge from the content presented through lessons as well as the context of their lessons' activities, rather than passively solely through information transmitted verbally or via rote memorization of notes taken from traditional lecture environments.

Project-based learning activities featured in Cornerstone environments include: collaborative/cooperative/peer learning in that projects are typically team-based and participative; just-in-time instruction in the form of lectures and class interactions that address issues instructors anticipate students will soon address; topic integration in that students must call upon many skills to diverge/converge towards their design solution; problem-based learning in the many smaller problems they encounter through the course of completing their project; and a context which mimics that of the professional environment in which most students will eventually find themselves. Students involved in these projects find themselves working with others to achieve a common goal, performing project management tasks, and communicating. Students communicate internally within their teams and externally with instructors and other classmates as a means to achieve the goal of realizing the project's end product. Students also formally communicate the results of the project through oral and written forms of technical communication. When compared to the traditional lecture environment, the enhanced environmental similarity of Cornerstone (and Capstone) experiences to the engineering workplace fosters more transferability and provides the student with importance and reason for 
that which they are learning through simultaneously applying content in the instructor-provided context as they learn it as shown by several studies reviewed by Prince and Felder ${ }^{2}$.

Teaching in a student-centered manner allows students to incur educational experiences that straddle many learning styles to satisfy the needs of the heterogeneous student body.

Project-based learning by its nature incorporates much of the spectrum of learning styles.

Project-based learning also invokes many pedagogical approaches and theories throughout its application.

\section{Purpose}

This study will investigate instructional scaffolding provided to students in cornerstone design project experiences by measuring student activities as students navigate various phases of the design process and manage their projects.

Questions considered in this study include:

- Is the design process and project management scaffolding provided to first-year engineering students in cornerstone experiences appropriate?

○ How much time do students spend on each phase of the design process and project management phases of the cornerstone design project?

$\circ$ What is the frequency of iterations in the phases of the design process and project management?

- When measured against actual student weekly activities, does the scaffolding provided match desired (expert) practices?

- How do these outcomes vary, if at all, across different cornerstone design projects?

\section{Theoretical Framework}

Vygotsky, the classical social constructivist, states that through the guidance and social interactions provided from mentors and capable peers in the social context, internal developmental processes are utilized and knowledge from actual experience in the social context is eventually re-constructed and internalized to expand the student's attained developmental level ${ }^{3}$.

Vygotsky defines the "Zone of Proximal Development" (ZPD) and the "actual developmental level" 3. The actual developmental level is defined as what a student can do independently, without the assistance of others. The ZPD is everything beyond that point which can be performed by the student with assistance. In Vygotsky's (translated) words, the ZPD "is the distance between the actual developmental level as determined by independent problem solving and the level of potential development as determined through problem solving under adult guidance or in collaboration with more capable peers",3. The Zone of Proximal Development is prospective development and should be the target area of instruction.

This assistance or support is required for the progression of learning and development and may come from mentors like instructional staff or peers such as teammates or classmates. This 
assistance or instructional support is referred to as "scaffolding" by modern contemporaries, a term credited to Bruner ${ }^{4}$. Scaffolding is any type of external aid or assistance provided directly by or developed in proxy by someone more capable, and can take the form of books, conversation, teamwork, computer-based exercises and instruction, questions, discussion, visual aid, or any cultural artifact in the social context which aids the learner in some manner in their ZPD as they internalize and re-construct that which they take from the social context.

Cornerstone design projects featuring student teams are inherently socially constructivist. The use of cooperative/peer learning, active learning, problem-based learning within the larger scope of a project-based learning environment featuring limited, interactive lecture, allows students to develop designs and gain design experience at a level at which they are capable with support structure provided by instructional staff that students may apply and reflect upon with their teammates and classmates. The layers and learning activities that exist within a term-length project-based learning environment also present adequate opportunities to address learning objectives at many levels ${ }^{5}$. Scaffolding does not have to be comprised solely of direct instructor interaction; in the cornerstone laboratory, scaffolding may take the form of texts, handouts, guides, diagrams, slides, notes, kitted equipment, a controlled work or laboratory environment, prepared data collection tools and equipment, prescribed, limited analysis tools and approaches, an introductory setting with instructor-established milestones, and the encouragement of divergence and convergence in the way students are thinking about their designs ${ }^{6}$ where appropriate. A strong case for increasing design in engineering education curricula is also made by Dym ${ }^{7}$.

\section{Literature Review}

Land and Zembal-Saul investigate technology-based scaffolds in a project-based learning environment ${ }^{8}$. They found that appropriate scaffolding can enhance student articulation and reflection and help students focus on the more educationally-relevant aspects of project-based learning tasks.

Shuman, Besterfield-Sacre, and McGourty discuss throughout their paper how ABET 2000 Creterion 3 Outcomes are addressed by student engineering design projects ${ }^{9}$. Dym reflects on design as an appropriate context for several of these outcomes ${ }^{10}$. Dym also recounts the difficulties of teaching design due to the multitude of technical and professional skills it incorporates. The benefits of project-based learning pedagogical applications for design are studied and documented by Davis, et al. ${ }^{11}$, Marra, Parra, and Litzinger ${ }^{12}$, and Mullins and $\operatorname{Atman}^{13}$, to name a few, as well as Dym et al. ${ }^{6}$, who summarize many of the prior findings.

Dym et al. ${ }^{6}$ thoroughly review and discuss the current state and literature of engineering design thinking, teaching, and learning, particularly from the perspective of project-based learning instructional strategy. Design thinking, the iterative processes and immense skill set required of designers, language and representation in design, the team-based nature and pedagogical advantages of team-based student design projects currently trending in post-secondary engineering education as well as varieties of project-based learning applications of engineering design education are reviewed. The authors discuss the advantages of problem-based learning approaches to engineering design education and engineering education as a whole as justified by 
the body of research as well as how these approaches address ABET 2000 criteria. Importantly and of particular relevance to the activities of this study, the authors call for "instrumenting the classroom" and new assessment techniques to complement the new instructional approaches and student activities in these design and engineering project-based learning environments, including gauging both student design quality and design process quality, and project-based learning and design process authenticity as compared to project and design processes in industry, among other opportunities.

Guidelines for project-based learning curriculum and activity development are suggested by Savage, Chen, and Vanasupa ${ }^{14}$, where they are implementing project-based learning throughout the entire four-year engineering curriculum, as several other institutions throughout the world have done ${ }^{2}$.

In Prince and Felder's summary of inductive teaching and learning methods ${ }^{2}$, they list projectbased learning as incorporating active, cooperative, and other features consistent with inductive learning. They also summarize characteristics of project-based engineering learning environments such as the roles of teams, instructional staff, and discuss applications and the extent to which students are given autonomy to define their projects.

There exists a multitude of engineering design and introductory engineering texts which define the design process as discrete and iterative sets of procedural steps within a cycle for the purposes of the novice. When several of these ${ }^{15-19}$ are viewed together and merged to form one consensus on the design process, where steps shown below with subcategories indicate that item may or may not be considered a separate phase, the resulting iterative five to eight step design process would be:

- Needs Identification, Problem Definition/Statement/Identification/Analysis

○ Requirements, Constraints, Limitations, Timing, Resources Identification

- Brainstorming, Design Concepts, Idea Generation, Alternatives

- Investigate, Test, Analyze, Evaluate Concepts/Ideas/Potential Solutions, Selections

- Modeling/Prototyping

- Investigate, Test, Analyze, Evaluate Models/Prototypes

- Detailed Design, Production/Working Drawings, Communication/Reporting/Presentation ○ Production, Marketing, Distribution

Freshman and senior level student application of and transitions within the design process are studied using short design scenarios ${ }^{20,21}$ where it is shown through verbal protocol analysis that senior level students showed greater numbers of transitions throughout information processing phases, possibly correlating to greater process efficiency, and a higher quality paper design.

\section{Case Study}

The Ohio State University's First-year Engineering Program (FEP) within the Engineering Education Innovation Center has focused on increasing retention by putting engineering "upfront" through hands-on laboratory experiences and design-build projects, commonly called "cornerstone" projects. This effort began as part of a nine-school coalition called the Gateway 
Engineering Education Coalition through the US National Science Foundation; and was in response to the growing concerns of poor retention rate, and some would say, the critical need for engineers in the early 1990s.

The FEP at its current state offers course sequences that include engineering fundamentals, technical graphics, engineering problem solving with computer programming, and hands-on laboratory experiences that lead to a design-build cornerstone project. There are three course sequences offered to first-year engineering student: Fundamentals of Engineering available to all students; Fundamentals of Engineering for Honors, designed to challenge the University Honors students; and the most recent Fundamentals of Engineering for Scholars in which the students are part of a living/learning community and are exposed to green engineering topics and sustainability issues.

These sequences are one of the most innovative of their kind and have received national recognition $^{22}$. Each year approximately 1,600 students complete the program through one of its course sequences. Currently four cornerstone design-build projects are offered through the course sequences that run for the full 10-week academic term:

1. the basics of potential and kinetic energy through model roller coasters,

2. a "lab-on-a-chip" done in micro-scale with nano-scale technology elements ${ }^{23}$,

3. fully-functional, small, autonomous, ground-based robots ${ }^{24-25}$, and

4. autonomous, advanced energy vehicles (AEV) that are suspended from and maneuver along a monorail track ${ }^{26}$.

\section{Common Elements}

There are a number of elements common to all of these team-based cornerstone projects. These elements happen to be similar to those forming three dimensions of the design learning domain that are fundamental to team-based engineering design documented in detail by Davis et al. ${ }^{11}$. Teams of four are formed, mentored, and reviewed to ensure that the students receive timely feedback on their performance and each design-build project share three main curriculum objectives:

1. Project Management and Teamwork - which includes, but is not limited to; time management and task scheduling, team communications and meetings, fair division of labor and team member responsibilities.

2. Design Process - which consists of: identifying the project requirements and constraints, gathering background information, brainstorming, identification of management of materials, preliminary analysis and initial design, and the build/test/modify/document cycle.

3. Project Documentation - which includes three parts:

i. Project notebook - complete documentation of the project, and which was reviewed on a weekly basis

ii. Final oral presentation - overview of design experience

iii. Final written report - complete summary of all aspects of the design 
FEP Scaffolding Use and Deliverables

One important objective for cornerstone design projects is to provide a team-based experience that includes all aspects of engineering design and development. This includes student exposure to all activities within the design process from initial concepts through prototype development and testing to a final product. This objective also includes successfully providing students with awareness of and experience with the iterative nature of design throughout the design cycle. It also includes application and maintenance of project management tools and techniques. In order to assess this objective, a student team-based survey was conducted on a weekly basis for each cornerstone project. The results are discussed in the following section.

At the beginning of the term for each cornerstone project, the students are provided with a detailed project description document that includes the project layout, the curriculum objectives, and in the case of the ground-based robot and AEV, that year's operational objectives. Two main technical references ${ }^{15,27}$ are used and each project shares a common instructional course format that includes: lectures on the technical approach to design; useful mathematical calculations needed; documentation methods for progress reports and a formal written report; requirements for an oral presentation; and various laboratory tools and techniques that are useful in completing the design. Lectures are given "just-in-time" and occupy less than one-third of the classroom time. Much of the scheduled class meeting time is set aside as an open lab setting where students are able to work on their design-build projects with instructors and teaching assistants available to answer questions, provide suggestions, and offer encouragement.

Student concerns are addressed and progress is closely monitored via a team-teaching approach with the use of graduate and undergraduate teaching assistants in the classroom and laboratories. In most cases the teaching assistants have been students in the FEP course sequences, and due to exceptional performance and abilities, were selected to return and mentor as teaching assistants.

Project management throughout the design process is regularly evaluated by requiring an updated project notebook. Each team tracks and manages the design-build project through notebook records that contain initial concepts, brainstorming notes, laboratory team memos, and in the case of the autonomous ground robots and AEV, weekly performance test summaries. The teams' final designs are evaluated during individual competitions and scored based on that year's design criteria. At the end of the project each team develops a final report and PowerPoint presentation to present as a team to the class and for evaluation by the instructional team. A final public competition or public exhibition, open to students and family members, industry support personnel, and the general public, brings all of the students together.

Student-team Based Survey

With the increasing enrollment rates, FEP is continuously learning and adapting to provide a successful undergraduate engineering cornerstone experience. One resource that is currently being used is a student team-based survey, conducted on a weekly basis for each cornerstone project. 
The surveying was anonymous and asked 72 teams, specifically 18 teams on each design project (or approximately 288 total students), to record time spent on design process activities. The design process for the design projects was broken into seven activities including project management, a main objective for each design project which includes time management, task scheduling, team communications, and meetings. The additional activities were selected based on the common activities, such as brainstorming and lab specific tasks geared toward their respective design project. The activities on the survey include: identifying solution options, identifying constraints, performing research, performing analysis, evaluating analysis, and implementing design decisions. The average percentage of total time spent for each activity throughout the design project and the number of times each student team revisited the activity on a weekly basis was recorded. This information was requested to provide insight into the students' experiences within the design cycle.

\section{Survey Results and Observations}

Figure 1, shows the breakdown of the average percentage of total time spent for each design activity for the combined four cornerstone projects, and is followed by similarly formatted representations for each corresponding individual design-build project in Figure 2.

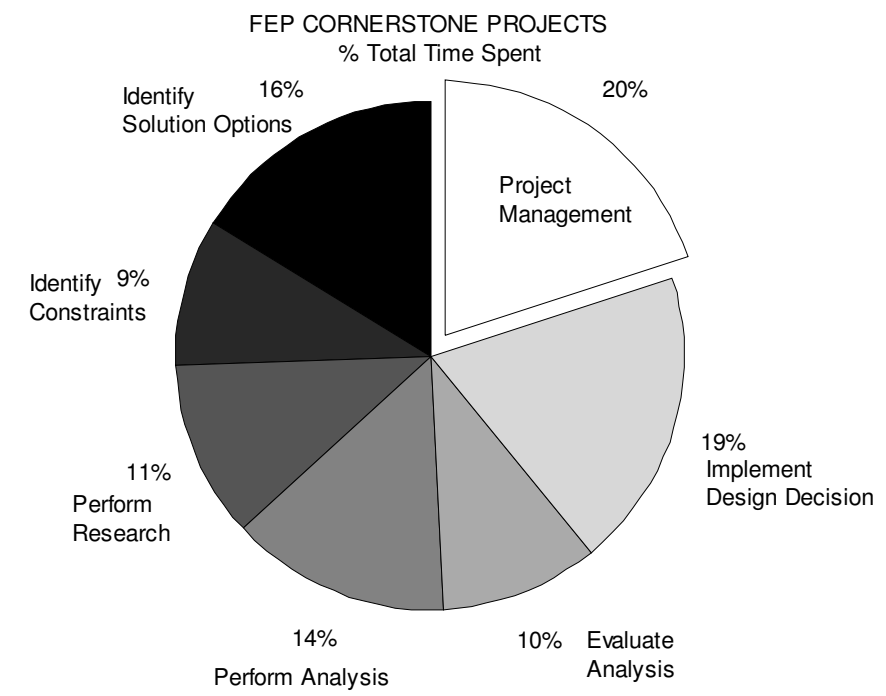

Figure 1: FEP Cornerstone Design Projects - Student Team Survey Results.

[\% Averaged Total Time Spent] 

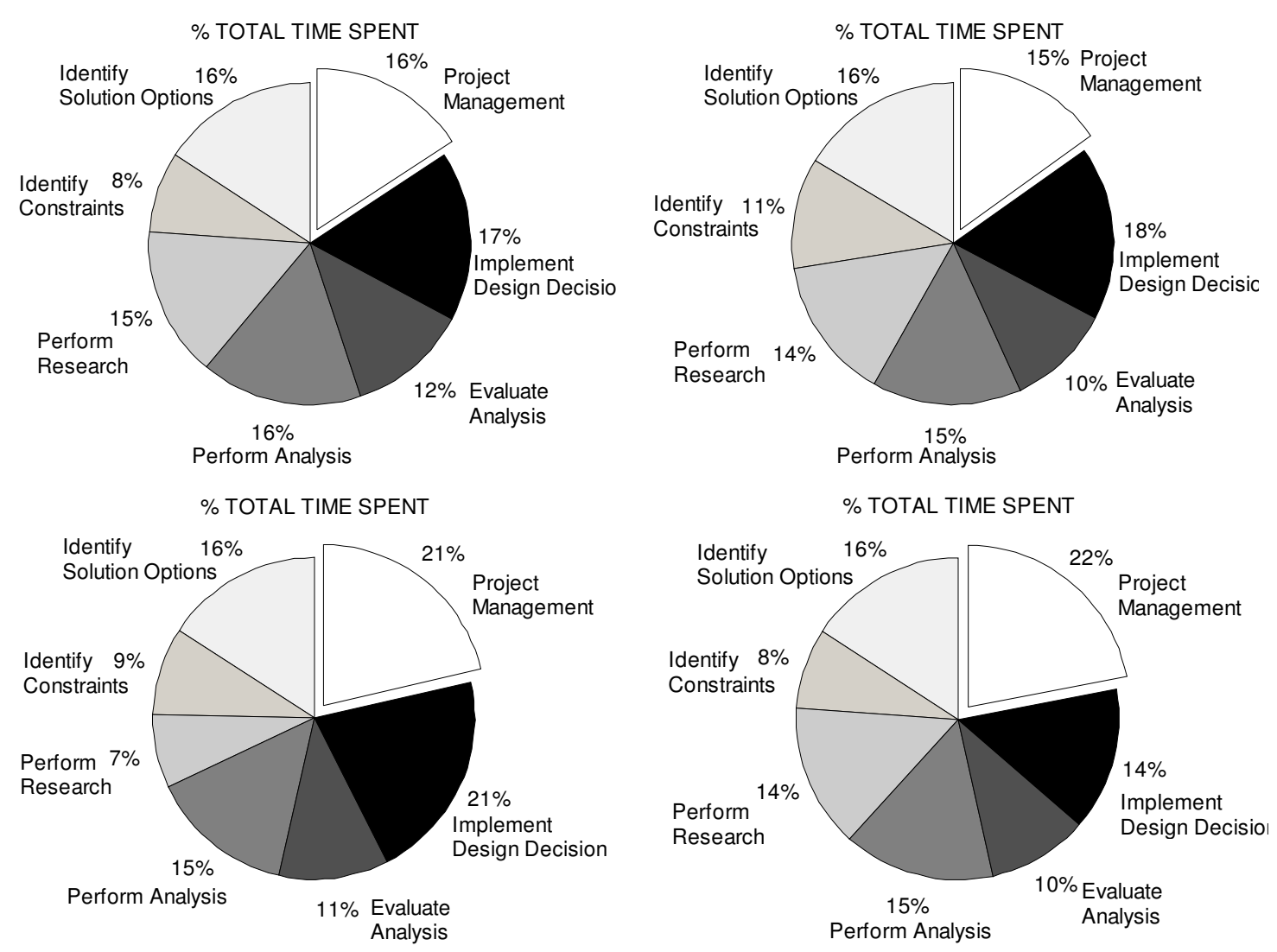

Figure 2: Cornerstone Design Project - Student Team Survey Results.

[Top-Left: Rollercoaster; Top-Right: Nano;

Bottom-Left: Robot; Bottom-Right: AEV]

The first observation for these four projects stems from design process activity data collected and shown in the above figures. Given that the seven design and project management activities in the weekly team-based survey represent a reasonably full set of activities for most any design project, it is encouraging that all the FEP cornerstone design projects incorporate a measureable amount of time spent performing each activity. Data reveal that students are getting exposure to and experience in all of these important design activities, with no specific activity receiving less than $7 \%$ of a team's attention.

Along with providing a design-build experience that incorporates a measureable amount of time spent for each activity, the occurrences of multiple visits to the design process activities highlight and reinforce the iterative nature of design for the students. Figure 3 shows the combined and averaged number of times the student team revisited the activity on a weekly basis. 
FEP CORNERSTONE PROJECTS

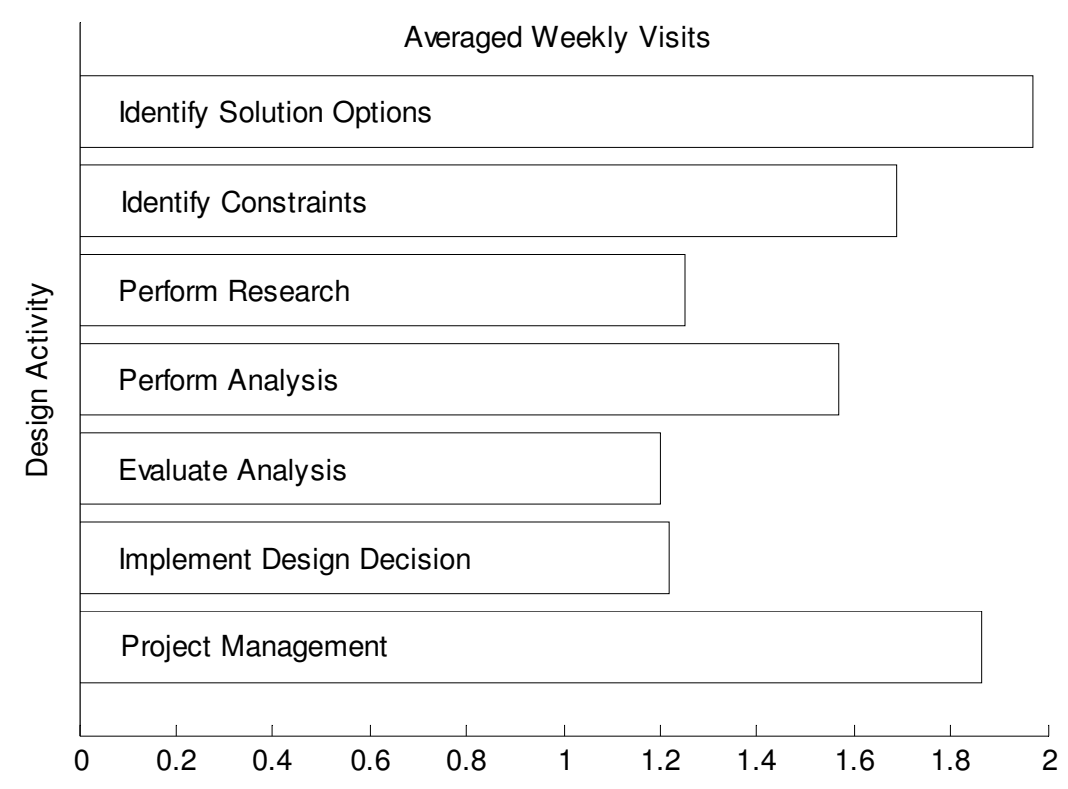

Figure 3: FEP Cornerstone Design Projects - Student Team Survey Results. [Averaged Weekly Visits]

It should be noted that more complex design problems invoke more visits and revisits to specific design activities as shown by further detailed review of the data for the Honors robot and Scholars AEV projects when compared to the other two projects ${ }^{28}$. The greatest number of visits and revisits occurs for the robot project in the areas of identifying constraints and identifying solution options, with both areas having over three visits per week. It should also be noted that the Honors robot project has approximately three times as much scheduled class meeting time available per week compared to the other three design projects.

Along with structured laboratory and classroom assignments, each design project provides time for student teams to explore the open-ended nature of design. The survey data demonstrate that balancing the structured laboratory experiences with the open-ended work sessions and/or performance tests provides time for the students to explore the iterative process of design within the design cycle.

\section{Discussion}

The implications of this investigation of project-based learning, whether concerning cornerstone, capstone, or other applications are significant in that the results of individual projects can be gauged against those of other student projects, and with some parsing and coding, perhaps realworld projects of professionals as well. In addition, the results of this investigation provide a foundation for confirming the effective emphasis of particular phases of the design process and project management throughout the project experience. 
Student behaviors throughout design projects in project-based learning environments like those described above can be compared to the tendencies of experts or professionals proficient in design and project management. The scaffolding itself or the manner in which features of it are emphasized (through the project itself, or artifacts such as the skeletal schedule the students receive as part of their project description documentation, for example) can be altered to more accurately reflect the habits of professional or expert designers. In addition, emphasis can be added where students are having difficulty constructing their own concepts in certain areas of the project.

Program leadership and faculty can use these results and observations to evaluate the student focus throughout the design and project management process and direct alterations in the scaffolding as they deem necessary. There is solace in the fact that students of different cornerstone projects, given proper scaffolding, experience similar emphasis on project phases and design process steps. No one cornerstone project stands out as excessively diverting student attention to any phase of design or project management compared to other projects documented, nor does any one area of design or project management overtly lack emphasis.

Scaffolding in project-based learning cornerstone experiences encourages designer-like behavior where students act like designers, project managers, and communicate status and results in a professional manner and thus serves the purpose of allowing novices to perform beyond the means of which they are capable without support. The scaffolding also allows for a set of activities which more closely mirror the activities of the professional whom faculty and future employers alike hope the students will one day become.

The items discussed in this investigation reflect the beginning of a more thorough consideration of the student designer roles that scaffolding in cornerstone project-based learning environments fosters. Expert designers will be each given a single anonymous survey which queries the participant on the desired outcomes regarding the specific design activities listed in the student team-based weekly surveys. Complementary investigations of faculty who teach engineering design and professionals engaged in engineering design would allow for comparisons between the students and the experts they strive to become. The insight gained from these comparisons could be used to further enhance scaffolding provided to design students to improve outcomes.

Current research and future extensions of this study will seek to include the design activities of students in senior capstone design projects. The aforementioned questions and considerations regarding student application of the design process and the scaffolding provided will be made again to include these capstone students. The progress post-secondary engineering students make from the cornerstone to the capstone level and to what degree design process scaffolding can be removed or changed will also be investigated. This investigation will include a discussion of where scaffolding should be added to support student progress as their zone of proximal development extends as students construct their own understandings of the design process with development and experience. Students will also be quizzed on hypothetical design scenarios to determine how they would propose to apply the design process in an unguided design situation to test their experiential learning and reflection. This post-survey is necessary to gauge whether students are actually learning how to apply a design process or just blindly following steps in the instructor-provided scaffolding to complete an assigned and graded project. 
These future directions for investigation beg the following questions for research:

- What inconsistencies may there be between the habits of student and professional designers, and what actions can be taken to address the lessons-learned?

- Given a benchmark of academic and professional expert design practices, how can and should scaffolding evolve or change as students develop?

- Does scaffolding appropriately change as students reach the capstone level?

- If there is a lack of adequate evolution of scaffolding, is it due to student preparedness, inappropriate scaffolding provisions by faculty, or a combination of both?

Summary and Conclusion

This study investigated the way students given design and project management scaffolding in a cornerstone design project allocated their time throughout the design process and project management phases. This study also documented the iterations student teams made throughout their projects. A truly comprehensive cornerstone project, in many respects, is comparable to the senior level "capstone" design course, and the two experiences act as bookends to the undergraduate engineering experience. It is for this reason that capstone design projects are currently being similarly investigated, and the results from both investigations will be compared to the input of faculty and professional designers for the purpose of informing curriculum designers on the best directions to take with efforts to improve scaffolding provided at the cornerstone and capstone level of engineering design projects in the post-secondary environment.

References

1. Felder, R. M., \& Silverman, L. K. (1988). Learning and teaching styles in engineering education. Engineering Education, 78(7), 674-681.

2. Prince, M. J., \& Felder, R. M. (2006). Inductive teaching and learning methods: Definitions, comparisons, and research bases. Journal of Engineering Education, 95(2).

3. Vygotsky, L. S. (1978). Mind in society: The development of higher psychological processes. Cambridge: Harvard University Press, p. 90, 85, 86.

4. Wood, D. J., Bruner, J. S., \& Ross, G. (1976). The role of tutoring in problem-solving. Journal of Child Psychology and Psychiatry, 17(2), 89-100, p.90.

5. Bloom, B. S., Engelhart, M. D., Furst, E. J., Hill, W. H., \& Krathwohl, D. R. (1956). Taxonomy of educational objectives: the classification of educational goals; Handbook I: Cognitive Domain New York: Longmans, Green.

6. Dym, C. L., Agogino, A. M., Eris, O., Frey, D. D., \& Leifer, L. J. (2005). Engineering design thinking, teaching, and learning. Journal of Engineering Education, 94(1), p. 112.

7. Dym, C. L. (1999). Learning engineering: Design, languages, and experiences. Journal of Engineering Education, 88(2). 
8. Land, S. M., \& Zembal-Saul, C. (2003). Scaffolding reflection and articulation of scientific explanations in a data-rich, project-based learning environment: An investigation of progress portfolio. Educational Technology Research and Development, 51(4), 65-84.

9. Shuman, L. J., Besterfield-Sacre, M., \& McGourty, J. (2005). The ABET "professional skills" — can they be taught? Can they be assessed? Journal of Engineering Education, 94(1).

10. Dym, C. L. (2007). Engineering design: So much to learn. International Journal of Engineering Education, 22(3), 422-428.

11. Davis, D.C., Gentili, K.L., Trevisan, M.S., Christianson, R.K., and McCauley, J.F. (2000). Measuring learning outcomes for engineering design education. Proceedings of the Annual Conference of the American Society for Engineering Education, Session 1625.

12. Marra, R. M., Palmer, B., \& Litzinger, T. A. (2000). The effects of a first-year engineering design course on student intellectual development as measured by the Perry Scheme. Journal of Engineering Education, 89(1), $39-45$.

13. Mullins, C. A., \& Atman, C. J. (1999). Freshman engineers' performance when solving design problems. IEEE Transactions on Education, 42(4).

14. Savage, R. N., Chen, K. C., \& Vanasupa, L. (2009). Integrating project-based learning throughout the undergraduate engineering curriculum. IEEE Engineering Management Review, 37(1), 25-37.

15. Dominick, P. G., Demel, J. T., Lawbaugh, W. M., Freuler, R. J., Kinzel, G. L., \& Fromm, E. (2001). Tools and Tactics of Design. New York: Wiley, pp.5-7.

16. Dym, C. L. (1994). Engineering Design: A Synthesis of Views. Cambridge: Cambridge University Press, p. 25.

17. Meyers, F. D., Croft, F. M., Miller, M. J., Demel, J. T., \& Enders, H. L. (2004). Technical Graphics. New York: Wiley, p. 13-4.

18. Ogot, M. M., \& Kremer, G. (2004). Engineering Design: A Practical Guide. Pittsburgh, PA: Togo Press, p.11.

19. Stephan, E. A., Bowman, D. R., Park, W. J., Sill, B. L., \& Ohland, M. W. (2011). Thinking Like An Engineer: An Active Learning Approach. Upper Saddle River, NJ: Pearson, pp. 43-44.

20. Adams, R., \& C. J. Atman (2000). Characterizing engineering student design processes: An illustration of iteration. Proceedings of the Annual Conference of the American Society for Engineering Education, St. Louis, Session 2330.

21. Atman, C. J., Cardella, M. E., \& Turns, J. (2005). Comparing freshman and senior engineering design processes: an in-depth follow-up study. Design Studies, 26(4), 325-57.

22. Demel, J.T., R.J. Freuler, and A.W. Fentiman. (2004). Building a successful fundamentals of engineering for honors program. Proceedings of the 2004 American Society for Engineering Education Annual Conference, Salt Lake City, Utah.

23. Allam, Y., Tomasko, D.L., Trott, B.C., Schlosser, P.A., Yang, Y., Wilson, T.M., \& Merrill, J.A. (2008). Labon-a-chip design-build project with a nanotechnology component in a freshman engineering course. Chemical Engineering Education, (42)4.

24. Freuler, R.J., Hoffmann, M.J., Pavlic, T.P., Beams, J.M., Radigan, J.P., Dutta, P.K., Demel, J.T., \& Justen, E.D. (2003). Experiences with a comprehensive freshman hands-on course - designing, building, and testing small 
autonomous robots. Proceedings of the 2003 American Society for Engineering Education Annual Conference, Nashville, Tennessee.

25. Vernier, M.A., Morin, C.E., Wensing, P.M., Hartlage, R.M., Carruthers, B.E., \& Freuler, R.J. (2009). Use of a low-cost camera-based positioning system in a first-year engineering cornerstone design project. Proceedings of the 2009 American Society for Engineering Education Annual Conference, Austin, Texas.

Also published in: (2010). Computers in Education Journal, (1)2, 6-14.

26. Whitfield, C.A., Schlosser, P.A., Merrill, J.A., Riter, E.A., \& Agarwal, K. (2011). Advanced energy vehicle design-build project for first-year engineering students. Proceedings of the 2011 American Society for Engineering Education Annual Conference, Vancouver, B.C.

27. Beer, D.F., \& McMurrey, D. (1997). A Guide to Writing as an Engineer. New York: Wiley.

28. Whitfield, C.A., Freuler, R.J., Allam, Y., Riter, E.A. (2011). An overview of highly successful first-year engineering cornerstone design projects. Proceedings of the 2011 International Conference on Engineering Education, Belfast, Ireland. 